\title{
Can psychiatric childhood disorders be due to inborn errors of metabolism?
}

\author{
A. Simons ${ }^{1,2,4}$ - F. Eyskens ${ }^{1}$ I. Glazemakers ${ }^{2,4,5} \cdot$ D. van West ${ }^{2,3,4,5}$
}

Received: 16 January 2016 / Accepted: 23 September 2016 / Published online: 30 September 2016

(C) The Author(s) 2016. This article is published with open access at Springerlink.com

\begin{abstract}
Many patients who visit a centre for hereditary metabolic diseases remarkably also suffer from a child psychiatric disorder. Those child psychiatric disorders may be the first sign or manifestation of an underlying metabolic disorder. Lack of knowledge of metabolic disorders in child psychiatry may lead to diagnoses being missed. Patients therefore are also at risk for not accessing efficacious treatment and proper counselling. To search the literature for the co-occurrence of child psychiatric disorders, such as ADHD, autism, psychosis, learning disorders and eating disorders and metabolic disorders. A search of the literature was conducted by performing a broad search on PubMed, using the terms "ADHD and metabolic disorders", "autism and metabolic disorders", "psychosis and metabolic disorders", "learning disorders
\end{abstract}

\section{A. Simons}

annik.simons@zna.be; anniksimons@hotmail.com

F. Eyskens

francois.eyskens@uza.be

I. Glazemakers

inge.glazemakers@uantwerpen.be

D. van West

dirk.vanwest@zna.be

1 Centre of Heriditary Metabolic Diseases Antwerp (CEMA), University Hospital of Antwerp (UZA), Wilrijkstraat, 2650 Edegem, Belgium

2 Collaborative Antwerp Psychiatric Research Institute (CAPRI) Youth, Antwerp, Belgium

3 University of Brussels, Brussels, Belgium

4 University Child and Adolescent Psychiatry Antwerp, Lindendreef 1, 2020 Antwerp, Belgium

5 University of Antwerp (CAPRI), Universiteitsplein 1, 2610 Wilrijk, Belgium and metabolic disorders", and "eating disorders and metabolic disorders". Based on inclusion criteria (concerning a clear psychiatric disorder and concerning a metabolic disorder) 4441 titles and 249 abstracts were screened and resulted in 71 relevant articles. This thorough literature search provides child and adolescent psychiatrists with an overview of metabolic disorders associated with child psychiatric symptoms, their main characteristics and recommendations for further investigations.

Keywords Metabolic disorders · Child psychiatric disorder · ASD · ADHD $\cdot$ Learning disorder · Psychosis · Eating disorder
Abbreviations
OXPHOS Oxidative phosphorylation
OTCD Ornithine transcarbamylase deficiency
3-OH-IVA 3-hydroxyisovaleric acid

\section{Introduction}

Although a lot of research has already been done about organic causes of child psychiatric disorders, few of them focus on metabolic disorders as a possible cause of a child psychiatric disorder. Many children who visit our centre for hereditary metabolic diseases suffer from a child psychiatric disorder [1]. Metabolic disorders cover a variety of diseases in which there is an accumulation of toxic and/or complex compounds or energy problems within the cells due to enzymatic defects or other protein dysfunction (e.g., transporter defects).

Sometimes the psychiatric symptoms occur before irreversible neurological lesions. A number of metabolic disorders give rise to a major psychiatric disorder. These 
Fig. 1 Flow diagram showing process of literature search

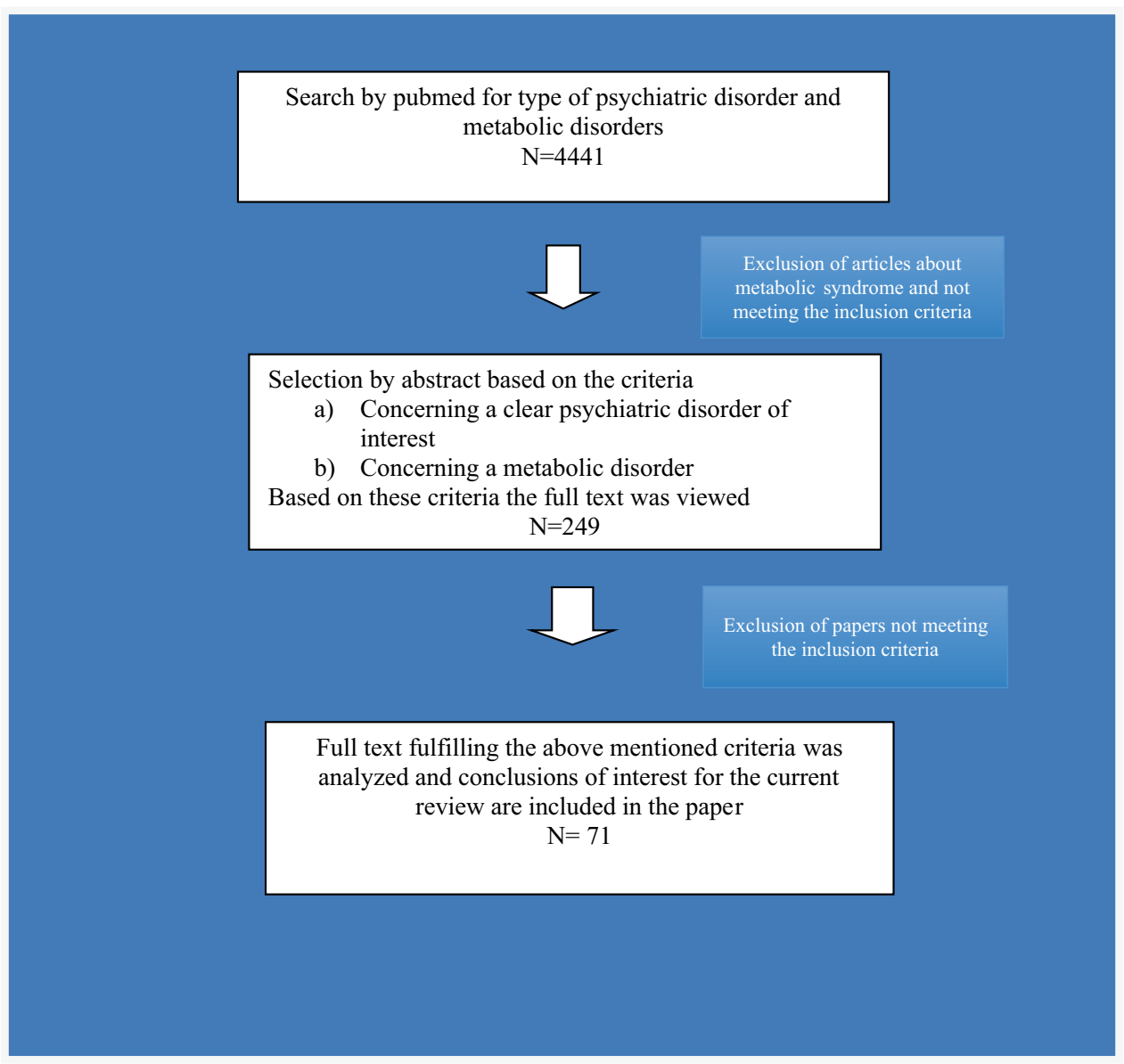

metabolic disorders can result in neuropsychiatric illness either through disruption of late neurodevelopmental processes, or via chronic or acute disruption of excitatory/ inhibitory or monoaminergic neurotransmitter systems. This disruption to metabolic processes can lead to gross neurodevelopmental disruption with seizures and coma, or to mild disruption with intermittent and/or subtle cognitive, behavioural disturbance and psychiatric illness, such as psychosis [2]. To prevent or decrease mortality, morbidity and disabilities associated with metabolic diseases as much as possible, it is important to detect the metabolic disease as early as possible. For this reason, it is important that child and adolescent psychiatrists are aware of possible underlying metabolic disease in child psychiatric problems. This is of great importance because specific treatment may be available to prevent metabolic decompensation and further progression of disease can be avoided. In addition, many of these conditions have important implications for genetic counselling. This article gives an overview of the literature on co-occurring metabolic disorders and child psychiatry disorders and attempts to give child psychiatrists some recommendations on when to screen for metabolic disorders.

\section{Method}

We searched PubMed for articles published between 1 January 1980 and 31 December 2013, using the search terms: "ADHD and metabolic disorders", "autism and metabolic disorders", "psychosis and metabolic disorders", "learning disorders and metabolic disorders", and "eating disorders and metabolic disorders". Concerning psychosis, we included articles about visual auditory or visual hallucinations, paranoid delusions, interpretative thoughts and schizophrenia. Articles were selected according the following criteria: (1) articles were written in English, (2) the article concerned a clear psychiatric disorder according the DSMcriteria and concerned a metabolic disorder, and (3) the article was not about a metabolic syndrome.

Our search resulted in 4441 initial hits, after screening titles and abstracts for inclusion and exclusion criteria, we studied the remaining 249 articles and concluded that only 71 were actually relevant (and not concerning the metabolic syndrome). Figure 1 shows the flow diagram that was used for all psychiatric disorders in the literature search; Table 1 specifies the search results for each psychiatric disorder separately. 
Table 1 Results of PubMed search by type of psychiatric disorder

\begin{tabular}{lccc}
\hline Type of psychiatric disorder & Number of titles found & Number of abstracts viewed & Numbers of articles included for review \\
\hline ADHD & 316 & 34 & 10 \\
Autism & 559 & 101 & 19 \\
Eating disorders & 1513 & 18 & 5 \\
Learning disorders & 726 & 49 & 17 \\
Psychosis & 1327 & 47 & 20 \\
Total (including review) & 4441 & 249 & 71 \\
\hline
\end{tabular}

Psychiatric disorders such a depression and anxiety disorders were not included in the search because based on clinical experience and earlier research [1], we expect these disorders rather to be a consequence of dealing with the diagnosis of and life with a metabolic disease than that they share a common underlying disruption.

\section{Literature search}

There is a lack of review articles on the subject. Only three reviews on psychiatric symptoms and metabolic disorders were found.

One by Sedel et al. [3] proposed a classification of metabolic diseases into three groups according to the type of psychiatric signs at onset. Group 1 represents psychiatric emergencies, namely acute and recurrent attacks of confusion and behavioural changes, sometimes misdiagnosed as acute psychosis. This includes urea cycle defects, homocysteine remethylation defects and porphyrias. Group 2 includes diseases with chronic psychiatric symptoms arising in adolescence or adulthood. These psychiatric symptoms can be recurrent psychotic attacks, chronic delusion or disorganized behaviour, and behavioural and personality changes. Among these diseases are homocystinurias, Wilson disease, adrenoleukodystrophy and some lysosomal storage disorders. Group 3 is characterized by mild mental retardation and late-onset behavioural or personality changes. This group includes homocystinurias, cerebrotendinous xanthomatosis, nonketotic hyperglycinemia, monoamine oxidase A deficiency, succinic semialdehyde dehydrogenase deficiency, creatine transporter defect, and alpha-/beta-mannosidosis. In this paper, a diagnostic strategy to guide metabolic investigations in a patient with atypical psychiatric signs is proposed.

Another article by Estrov et al. [4] reviewed four metabolic diseases: phenylketonuria (PKU), Wilson disease, acute intermittent porphyria (AIP) and metachromatic leukodystrophy (MLD). Early treated PKU can exhibit depressed mood, anxiety (esp agoraphobia) and psychosocial difficulties. Wilson disease can present with personality changes, depressive episodes, cognitive dysfunction and psychosis. AIP is often associated with symptoms of anxiety, depression, psychosis and altered mental status as psychiatric manifestations. MLD frequently presents with psychosis followed by intellectual deterioration.

In 2013, Walterfang et al. [2] wrote a review on the neuropsychiatry of inborn errors of metabolism. In this article, following metabolic disorders are also associated with psychiatric symptoms: metachromatic leukodystrophy, GM2 gangliosidosis, adrenoleukodystrophy, Niemann-Pick type $\mathrm{C}$ disease, cerebrotendinous xanthomatosis, neuronal ceroid lipofuscinosis, alpha-mannosidosis, Fabry disease, AIP, maple syrup urine disease, urea cycle disorders, disorders of homocysteine metabolism and PKU. Remarkably, there is an increase in reports the latest years about mitochondrial dysfunctioning and several neurodevelopment disorders, such as ASD, learning disorders, ADHD, schizophrenia and mood disorders [5, 6]. A mitochondrial dysfunction leads to an energy problem and neural synapses are areas of high energy consumption.

\section{Autism spectrum disorders}

About the link of autism spectrum disorder (ASD) and metabolic disorders four review articles were found [7-9]. In these four reviews, concerning ASD and metabolic disorders, similar findings are reported. Known metabolic disorders in autism are phenylketonuria, disorders in purine metabolism (such as adenosine deaminase deficiency, adenylosuccinate lyase deficiency, dihydropyrimidine dehydrogenase and dihydropyrimidinase deficiencies), organic acidurias (such as propionic academia, 3-methylcrotonyl-CoA carboxylase deficiency and pyridoxine dependency), disorders of branched-chain amino acids creatine deficiency, biotinidase deficiency, cerebral folate deficiency, succinic semialdehyde dehydrogenase deficiency, Smith-LemliOpitz syndrome (SLOS), late infantile ceroid lipofuscinosis, histidinemia, Sanfilippo disease, glucose 6-phosphate dehydrogenase deficiency, urea cycle disorders, X-linked ichthyosis, and mitochondrial disorders. In most of these disorders, there is also mental or psychomotor retardation.

In addition, case reports and some small studies about these diseases were found [10-14]. Benvenuto 
[15] names PKU, adenylosuccinase deficit, SLOS, creatine deficiency syndromes and mitochondrial disorders as possible causes of syndromic autism. Case reports of autism in association with acute intermittent porphyria [16], propionic academia [17] and L-2-hydroxyglutaric aciduria [18] were found. Kaluzna-Czaplinska [19] focusses on the role of homocysteine in autism. A high level of blood and urinary homocysteine is associated with pathophysiology of ASD and may serve as a diagnostic tool for the detection of nutrient deficiencies (folate, vitamin B12) in autistic children. The last years several studies were done suggesting a disturbance of mitochondrial energy production as an underlying pathophysiological mechanism in autism [20-22]. Frye [6] states that children with ASD and a mitochondrial disorder appear to have a higher prevalence of medical disorders such as gastrointestinal problems, seizures and gross motor delay. An interesting study was done in Greece [23] where they screened 187 children with confirmed features of ASD for the presence of inborn errors of metabolism. Their data provide evidence for a new biomarker (3-OH-IVA) and novel treatment approaches in ASD patient. Biotin supplementation or institution of a ketogenic diet resulted in mild to significant clinical improvement in the autistic features. Table 2 summarizes, based on the literature, when ASD is combined with specific other psychiatric, neurodevelopmental or somatic problems with metabolic diseases can be an underlying cause.

\section{Attention deficit hyperactivity disorder}

The literature search found several studies concerning the prevalence of attention deficit hyperactivity disorder (ADHD) in persons with a metabolic disorder. Knerr [11] studied a population of 33 subjects with succinic semialdehyde dehydrogenase deficiency of which $28 \%$ showed behavioural problems such as attention deficit and hyperactivity. In addition, autistic features were found in these patients. The patients in this population also have psychomotor retardation. In a population of 25 boys with X-linked ichthyosis [14], $40 \%$ fulfilled DSM-IV criteria for a diagnosis of ADHD. ADHD in children with PKU is well documented in several papers. Antshel [24, 25] stated that prenatal exposure to elevated levels of phenylalanine is associated with a higher likelihood of expressing hyperactive/impulsive symptoms and postnatal exposure is associated with a higher likelihood of expressing inattentive symptoms. Arnold [26] performed a study in 38 children with PKU and found that $26 \%$ of this children use stimulant medication for attentional dysfunction, which is significantly higher than in an age- and sex-matched control group. Case reports of ADHD in a child with a metabolic disorder were found for 3-methylcrotonyl-CoA carboxylase deficiency [27], argininosuccinate lyase deficiency [28] and succinyl-CoA: 3-oxoacid CoA transferase deficiency [29].

Wijburg et al. [30] stated that mucopolysaccharidosis III (Sanfilippo disease), which is characterized by progressive cognitive decline and severe hyperactivity, is often misdiagnosed as an idiopathic developmental delay, ADHD or ASS. ADHD is also linked to mitochondrial disorders [5]. An overview of the metabolic disorders associated with ADHD is summarized in Table 3.

\section{Learning disorders}

Taking learning disorders into consideration, some reports are found showing a link between learning disorders and adrenoleukodystrophy [31, 32] and MLD [33], which is associated with nonverbal learning disability. Gordon [34] reported about glucose transporter type 1 deficiency as a preventable cause of severe learning difficulties. Children with PKU show lower IQ, slow information processing, reduced learning capacity, mild executive impairments, and educational difficulties [35]. Antshel [24, 25] also reports in a review that young adults with PKU are more likely to have academic difficulties than their non-PKU peers, especially in maths. This is due to ADHD but also to executive functioning deficits and processing speed deficits. Janzen [36] stated that individuals with PKU also have nonexecutive cognitive abilities, such as problems with information speed processing, fine motor control, and perception and visualspatial abilities. In an American longitudinal observation with 108 individuals with urea cycle disorders, $35 \%$ had learning disabilities [37]. Lichter [38] specified this for OTC-deficiency. Special emphasis in this article was made on the late-onset (partial) disease, who can present from infancy to adulthood. A hyperammonemic crisis can lead to a life-threatening event and neuropsychological complications, such as developmental delay, ADHD and executive function deficits. Potter [39] studied 43 children with galactosemia and a history of speech sound disorders. $56 \%$ of the children with typical cognitive development and $88 \%$ of the children with borderline-low cognitive development showed language impairments. The first group had more often an expressive language disorder, the second group more often a mixed receptiveexpressive language disorder. Bahi-Buisson [40] examined 22 patients with hyperinsulinism-hyperammonaemia syndrome and found a learning disability in 17 patients. Case reports were found about the occurrence of learning disorders in glutaric aciduria type I [41] and generalised uridine diphosphate galactose-4-epimerase deficiency [42]. Learning difficulties are also reported in NiemannPick disease type C [43]. Patients with juvenile neuronal 


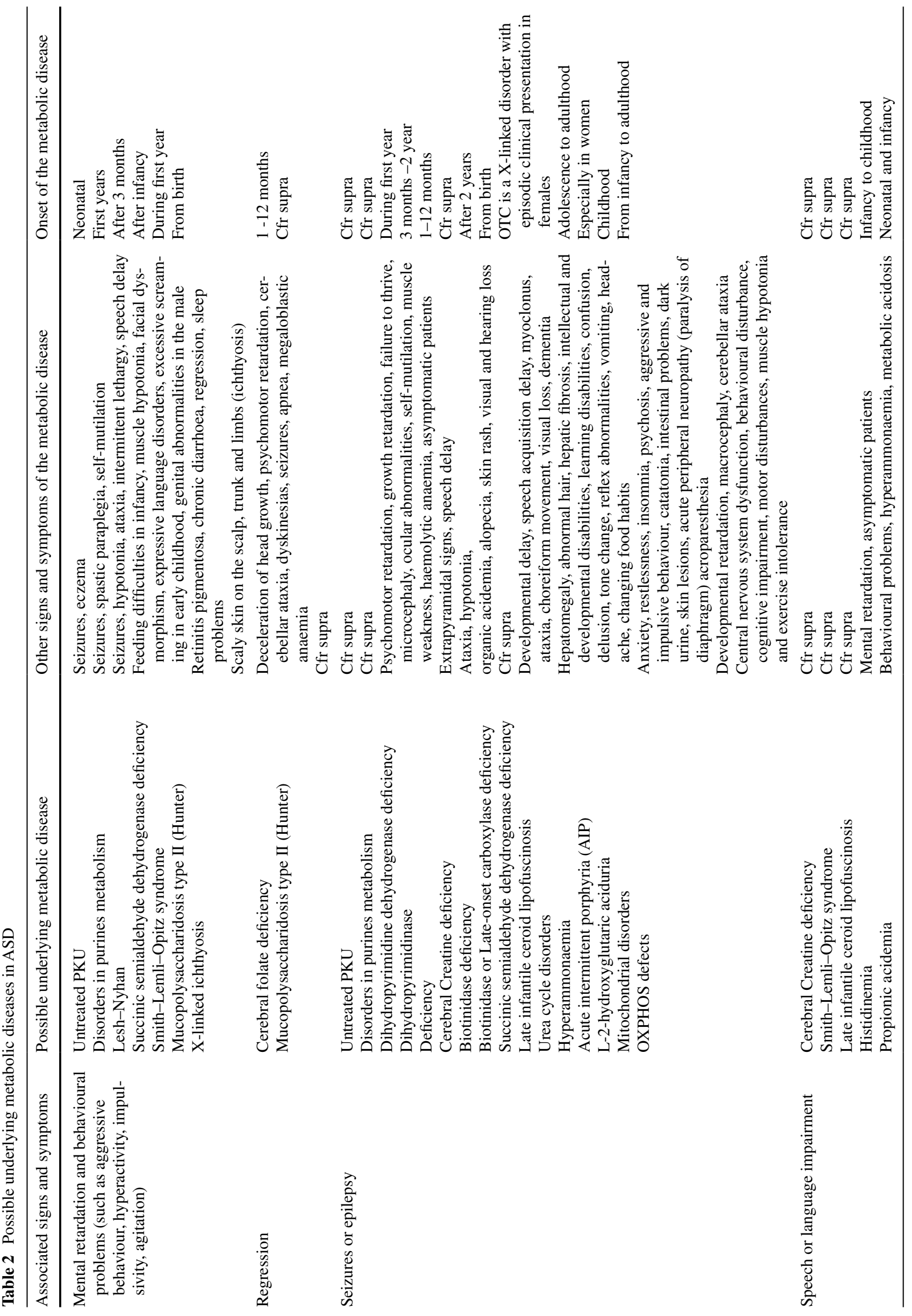




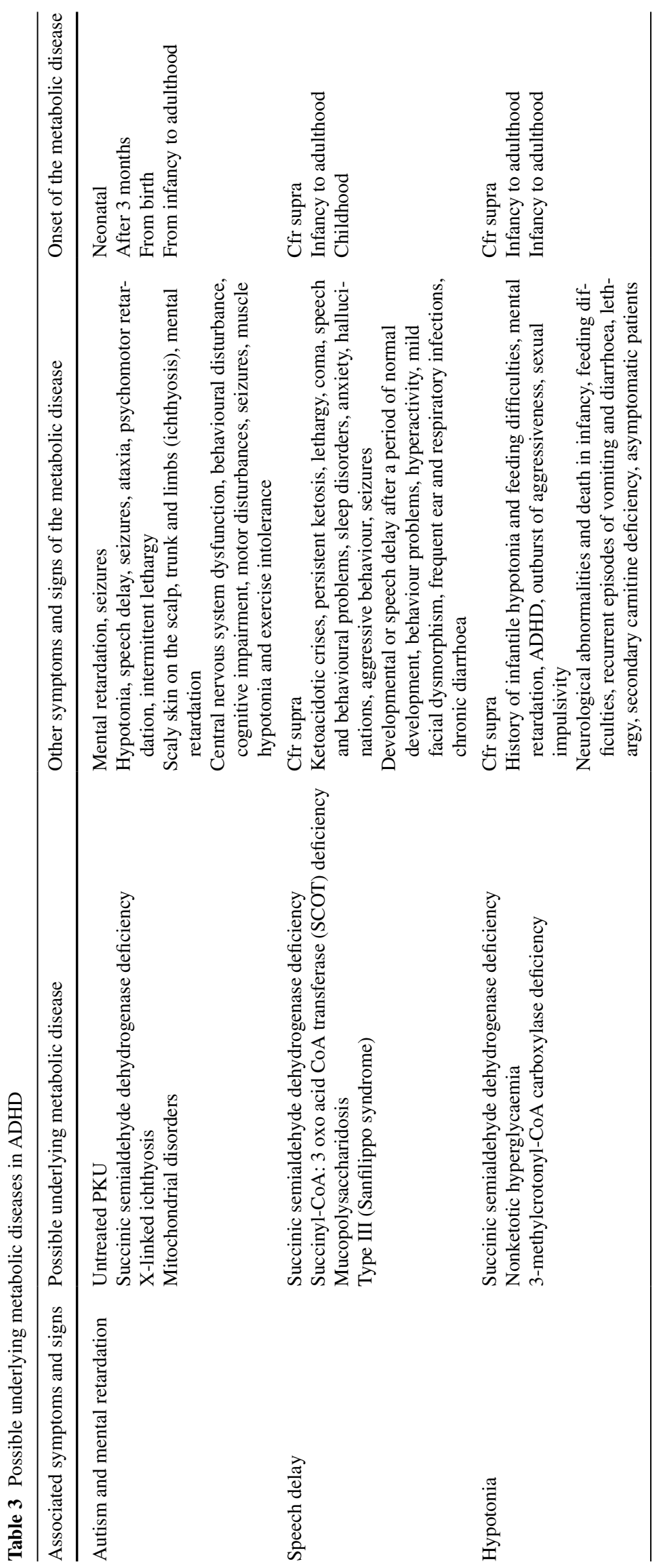


ceroid lipofuscinosis show learning delay and regression of acquired skills [44]. Brady [45] described two cases with mucopolysaccharidosis type IIIB presenting as children with behavioural issues and mild learning disabilities, and having a rapid cognitive decline in early adulthood (see Table 4 for an overview).

\section{Psychosis}

Psychosis, what can be auditory or visual hallucinations, paranoid delusions, and interpretative thoughts, and can be a symptom of schizophrenia, is described in alpha-mannosidosis [46, 47] and also in other lysosomal storage diseases: late-onset Tay-Sachs disease [48] and Fabry disease [49, 50]. Psychosis is also seen in mitochondrial disorders, in particular, respiratory chain defects $[5,51,52]$. Wilson's disease can present with psychosis, but also as personality and mood changes, depression, phobias, cognitive impairment, anxiety and compulsive and impulsive behaviour [5355]. A clinical presentation of metachromatic leukodystrophy during adolescence and/or adulthood may be psychosis [56]. If a post pubertal patient presents with acute mental changes and hallucinations or psychosis, acute porphyria should be considered [57]. In addition, a link between a disturbed homocysteine metabolism and schizophrenia is described [58]. Psychosis is also described in Niemann-Pick type C [59, 60]. Also, behavioural disturbances occur in this disease (see Table 5 for an overview).

\section{Eating disorders}

Concerning eating disorders and metabolic disorders only five relevant articles were found. Touati [61] describes frequent feeding disorders in children with methylmalonic and propionic acidurias, in which up to $60 \%$ of patients needed a food supplement by tube. Deutsch et al. [62] report about a woman with anorexia nervosa and a mitochondrial myopathy, suggesting the possibility that the eating disorder was causally related to a more fundamental defect in mitochondrial oxidative metabolism. Symptoms of anorexia nervosa were also described in MELAS [63] and mitochondrial encephalomyopathy [64]. Sedel [3] mentions in his review that patients with a urea cycle disorder often experience protein intolerance and change their food habits becoming vegetarian or anorexic. Also, Gardeitchik [65] reports that protein aversion can be a diagnostic clue in patients presenting with food refusal, recurrent vomiting, behavioural problems, mental retardation and episodes of altered consciousness (see Table 6 for an overview).

\section{Conclusions}

The literature search concerning metabolic disorders and child psychiatric disorders was performed. Metabolic diseases represent rare but important causes of psychiatric diseases that remain isolated for years before more specific organic signs become obvious [3]. Psychiatrist should be aware of inborn errors of metabolism. In the literature, most relevant articles were found concerning ASD and psychosis in combination with a metabolic disorder. Based on the literature an overview for the different psychiatric disorders in the scoop of this paper was made in the combination with others signs and symptoms. This overview gives the child and adolescent psychiatrist some direction for further investigations and referral to a metabolic unit.

In the literature search, no guidelines were found when to look for a metabolic disease in a child presenting with a psychiatric disorder. A broad metabolic screening or routine metabolic screening carriers a low yield [8]. A metabolic work-up must be reserved for patients with clinical indicators of a metabolic disorder [8, 15, 66].

Further investigations are warranted in case of $[3,8,15]$ :

- A positive family history of metabolic disease.

- Symptoms or signs are triggered by food intake (esp high protein content foods), fever, fasting, surgery (catabolism).

- Feeding difficulties, food refusal, failure to thrive, eating disorders combined with symptoms of myopathy or fatigue.

- Mental retardation and/or regression.

- Epilepsy, episodes of lethargy or confusion.

- Dysmorphic feature.

In most cases, there is a combination of neurological signs (epilepsy, ataxia, and catatonia), cognitive and motor dysfunction (hypotonia, hypertonia) and systemic signs of diverse organic involvement, cardiomyopathy, liver dysfunction, renal problems, immune deficiency, anaemia, and gastrointestinal problems (diarrhoea, obstipation, and pseudo-obstruction).

In this review, we did not include depression and anxiety disorders. The reason for this is that the focus of this review is on metabolic disorders as a comorbidity sharing similar pathogenesis, and a child psychiatric disorder being a clue to think about a metabolic disorder. In clinical practice, we see depression and anxiety after the diagnosis of a metabolic disorder, but rarely as a predictor of a metabolic disorder $[1,4]$. Nevertheless, in the process of the literature search, we found a few metabolic diseases presenting with depressive episodes or anxiety such as Wilson disease and AIP [4] (see also Table 5). 
Table 4 Possible underlying metabolic disease in learning disorders

Associated signs and symptoms Possible underlying metabolic disease

Neurodegeneration

Seizures

Vomiting and/or diarrhoea

Galactosemia

Urea cycle disorders

Mucopolysaccharidosis

Type III (Sanfilippo syndrome)

\author{
Adrenoleukodystrophy \\ (X-linked) \\ Metachromatic leukodystrophy \\ Glutaric aciduria type 1 \\ Mucopolysaccharidosis \\ Type III (Sanfilippo syndrome)
}

Untreated PKU

Glucose transporter type 1 deficiency

Hyperinsulinism-Hyperammonaemia syndrome

Urea cycle disorders

Juvenile neuronal ceroid lipofuscinosis
Other symptoms and signs of the metabolic disease

Variable phenotype, deterioration in school performance, dementia, vision loss, sensorineural hearing loss, brain white matter abnormalities on MRI, adrenal insufficiency

Progressive neurodegeneration. Nonverbal learning disability syndrome, spasticity, brain white matter abnormalities, peripheral neuropathy

Acute regression after an initial phase of (almost) normal development (acute encephalopathic crisis), severe dystonic-dyskinetic movement disorder, macrocephaly, MRI of the brain: fronto-temporal atrophy

Developmental or speech delay after a period of normal development, behaviour problems, hyperactivity, mild facial dimorphism, frequent ear and respiratory infections, chronic diarrhoea

Autism, ADHD, mental retardation, executive impairment

Delayed development in infancy with acquired microcephaly (cerebral/ cerebellar atrophy), ataxia

Hypoglycaemia, weakness, shakiness, rapid pulse, confusion

Hepatomegaly, abnormal hair, hepatic fibrosis, intellectual and developmental disabilities, learning disabilities, tone change, reflex abnormalities, vomiting

Progressive deterioration of cognition, ataxia, spasticity, vision loss, learning delay, regression of acquired skills

Lethargy, vomiting, diarrhoea, failure to thrive, jaundice, cataract, speech difficulties, learning disorders, tremor, ovarian failure, osteoporosis Cfr supra Cfr supra
Onset of the metabolic disease

Childhood to adulthood Infancy to adulthood 6 months to 2 years

Childhood

Neonatal

Neonatal

Infancy

From birth on Infancy to adulthood

Infancy to childhood

Cfr supra

Cfr supra
This review is written from the perspective of a child and adolescent psychiatrist. The literature shows us that psychiatric diseases in adulthood can also reveal a metabolic disorder [3]. For instance, postpartum psychosis can be caused by a urea cycle disorder [67-69] and by GM2 gangliosidosis [70] and psychosis is also described in methylenetetrahydrofolate reductase deficiency
(MTHFR) [71]. Therefore, knowledge of metabolic disease and their psychiatric manifestations is also warranted for adult psychiatrists. Finally, we hope to encourage the inclusion of inborn errors of metabolism in the differential diagnosis of psychiatric disease when appropriate as to allow and facilitate a prompt and correct diagnosis, followed by an effective treatment. 
Table 5 Possible underlying metabolic diseases in psychosis

\begin{tabular}{|c|c|c|c|}
\hline $\begin{array}{l}\text { Associated signs } \\
\text { and symptoms }\end{array}$ & $\begin{array}{l}\text { Possible underlying metabolic } \\
\text { disease }\end{array}$ & $\begin{array}{l}\text { Other symptoms and signs of the metabolic } \\
\text { disease }\end{array}$ & Onset of the metabolic disease \\
\hline Seizures & $\begin{array}{l}\text { Mitochondrial disorders } \\
\text { Acute intermittent porphyria (AIP) } \\
\text { Urea cycle disorders } \\
\text { Methylenetetrahydrofolate reduc- } \\
\text { tase deficiency }\end{array}$ & $\begin{array}{l}\text { Central nervous system dysfunction, behavioural } \\
\text { disturbance, cognitive impairment, motor distur- } \\
\text { bances, autism } \\
\text { Anxiety, restlessness, insomnia, neuropathy, } \\
\text { psychosis, aggressive and impulsive behaviour, } \\
\text { catatonia, intestinal problems, dark urine, skin } \\
\text { lesions, epilepsy, acute peripheral neuropathy } \\
\text { Hepatomegaly, abnormal hair, hepatic fibrosis, } \\
\text { intellectual and developmental disabilities, } \\
\text { learning disabilities, confusion, delusion, seizure } \\
\text { disorders, muscle tone change, reflex abnormali- } \\
\text { ties, vomiting, changing food habits, headache } \\
\text { Mild or severe depending on the enzyme activity: } \\
\text { encephalopathy, gait disturbance, parapare- } \\
\text { sis, arterial or venous thrombosis and strokes, } \\
\text { neurocognitive impairment, feeding problems, } \\
\text { spasticity }\end{array}$ & $\begin{array}{l}\text { Infancy to adulthood } \\
\text { Adolescence and adulthood } \\
\text { Infancy to adulthood } \\
\text { Infancy to adulthood }\end{array}$ \\
\hline Mental retardation & $\begin{array}{l}\text { Alpha- } \\
\text { Beta-mannosidosis } \\
\text { Niemann-Pick type C } \\
\text { Homocystinuria }\end{array}$ & $\begin{array}{l}\text { Immune deficiency, facial and skeletal abnormali- } \\
\text { ties, hearing impairment, intellectual disability, } \\
\text { progressive neurological signs, episodes of } \\
\text { confusion and psychosis followed by a period of } \\
\text { confusion, somnolence and asthenia } \\
\text { Hepatosplenomegaly, cerebellar ataxia, dysar- } \\
\text { thria, vertical gaze palsy, cognitive difficulties, } \\
\text { progressive neurological deterioration, psychotic } \\
\text { symptoms, schizophrenia, behavioural distur- } \\
\text { bances (aggressiveness, self-mutilation, social } \\
\text { isolation, laughing), depressive episodes, bipolar } \\
\text { disorders, obsessive-compulsive disorders, } \\
\text { infantile cholestatic icterus } \\
\text { Lens dislocation, Marfan-like appearance, throm- } \\
\text { boembolic events, schizophrenia or psychotic } \\
\text { episodes (rare), behavioural disorders, depres- } \\
\text { sion, obsessive-compulsive disorder, disorgan- } \\
\text { ized behaviour, delusions, depression, alteration } \\
\text { of consciousness, peripheral neuropathy, coma, } \\
\text { paraplegia, strokes, thromboembolic events }\end{array}$ & $\begin{array}{l}\text { Infancy } \\
\text { From childhood to adolescence } \\
\text { Infancy to adulthood }\end{array}$ \\
\hline Depression & $\begin{array}{l}\text { Wilson's disease } \\
\text { Fabry's disease } \\
\text { (X-linked) } \\
\text { Tay-Sachs/ } \\
\text { Sandhoff disease or GM2 gangli- } \\
\text { osidosis } \\
\text { Niemann-Pick type C Homocyst- } \\
\text { inuria }\end{array}$ & $\begin{array}{l}\text { Ophtalmology: Kayser-Fleisher rings mood } \\
\text { disorders, behavioural and personality disorders, } \\
\text { cognitive impairment, psychotic symptoms, } \\
\text { dysarthria, anxiety } \\
\text { Neural pain in hands and feet, cornea verticil- } \\
\text { lata, hearing loss, stroke, renal dysfunction, } \\
\text { proteinuria, asymmetric cardiac hypertrophy, } \\
\text { angiokeratoma } \\
\text { Speech and swallowing difficulties, unsteadiness } \\
\text { of gait, spasticity, dystonia, cognitive decline, } \\
\text { schizophrenia like psychosis, depression, mania, } \\
\text { lower motor neuron disease, sensitive polyneu- } \\
\text { ropathy, dysautonomia, spastic fright reaction, } \\
\text { ophthalmology: cherry red spot, blindness } \\
\text { Cfr supra } \\
\text { Cfr supra }\end{array}$ & $\begin{array}{l}\text { Adolescence and adulthood } \\
\text { Adolescence and adulthood } \\
\text { Infancy to adulthood } \\
\text { Cfr supra } \\
\text { Cfr supra }\end{array}$ \\
\hline
\end{tabular}


Table 6 Possible underlying metabolic diseases in eating disorders

\begin{tabular}{lll}
\hline Possible underlying metabolic disease & Other symptoms and signs of the metabolic disease & Onset of the metabolic disease \\
\hline $\begin{array}{l}\text { Mitochondrial neurogastrointestinal encephalomyopa- } \\
\text { thy (MNGIE) }\end{array}$ & $\begin{array}{c}\text { Severe cachexia, gastrointestinal dysmotility, progres- } \\
\text { sive external ophthalmoplegia, peripheral neuropathy }\end{array}$ & Infancy to adulthood \\
$\begin{array}{l}\text { Mitochondrial encephalopathy lactic acidosis and } \\
\text { stroke-like episodes (MELAS) }\end{array}$ & $\begin{array}{c}\text { Mitochondrial encephalomyopathy, lactic acidosis, and } \\
\text { stroke-like episodes }\end{array}$ & Infancy to adulthood \\
Methylmalonic and propionic aciduria & $\begin{array}{l}\text { Developmental delay, cardiomyopathy, renal failure, } \\
\text { opticus atrophy }\end{array}$ & From birth \\
Urea cycle disorders & $\begin{array}{l}\text { Hepatomegaly, abnormal hair, hepatic fibrosis, intel- } \\
\text { lectual and developmental disabilities, learning } \\
\text { disabilities, confusion, delusion, seizure disorders, }\end{array}$ & Infancy to adulthood \\
muscle tone change, reflex abnormalities, vomiting, & \\
headache, changing food habits &
\end{tabular}

\section{Compliance with ethical standards}

Conflict of interest On behalf of all authors, the corresponding author states that there is no conflict of interest.

Open Access This article is distributed under the terms of the Creative Commons Attribution 4.0 International License (http://creativecommons.org/licenses/by/4.0/), which permits unrestricted use, distribution, and reproduction in any medium, provided you give appropriate credit to the original author(s) and the source, provide a link to the Creative Commons license, and indicate if changes were made.

\section{References}

1. Simons A, Eyskens F, De Groof A, Van Diest E, Deboutte D, Vermeiren $R$ (2006) Cognitive functioning and psychiatric disorders in children with a metabolic disease. Eur Child Adolesc Psychiatry 15:207-213

2. Walterfang M, Bonnot O, Mocellin R, Velakoulis D (2013) The neuropsychiatry of inborn errors of metabolism. J Inherit Metab Dis 36:687-702

3. Sedel F, Baumann N, Turpin J, Lyon-Caen O, Saudubray J, Cohen D (2007) Psychiatric manifestations revealing inborn errors of metabolism in adolescents and adults. J Inherit Metabol Dis 30:631-641

4. Estrov Y, Scaglia F, Bodamer OA (2000) Psychiatric symptoms of inherited metabolic disease. J Inherit Metabol Dis 23:2-6

5. Marazziti D, Baroni S, Pichetti M, Landi P, Silvestri S, Vatteroni E et al (2012) Psychiatric disorders and mitochondrial dysfunctions. Eur rev Med Pharmacol Sci 16:270-275

6. Frye R, Rossignol D (2012) Mitochondrial and metabolic abnormalities in neurodevelopmental disorders. $\mathrm{J}$ of Ped Biochem 2:177-180

7. Ghaziuddin M, Al-Owain M (2013) Autism spectrum disorders and inborn errors of metabolism: an update. Pediatr Neurol 49:232-236

8. Zecavati N, Spence S (2009) Neurometabolic disorders and dysfunction in autism spectrum disorders. Curr Neurol Neurosci Rep 9:129-136

9. Manzi B, Loizzo A, Giana G (2008) Curatolo. Autism and metabolic diseases. J Child Neurol 23:307-314

10. Knerr I, Gibson K, Jakobs C, Pearl P (2008) Neuropsychiatric morbidity in adolescent and adult succinic semialdehyde dehydrogenase deficiency patients. CNS Spectr 13:598-605
11. Jurecka A, Zikanova M, Tylki-Szymanska A, Krijt J, Bogdanska A, Gradowska W et al (2008) Clinical, biochemical and molecular findings in seven Polish patients with adenylosuccinate lyase deficiency. Mol Genet Metab 94:435-442

12. Gorker I, Tuzun U (2005) Autistic-like findings associated with a urea cycle disorder in a 4-year-old girl. J Psychiatry Neurosci 30:133-135

13. Kent L, Emerton L, Bhadravathi V, Weisblatt E, Pasco G, Willatt L et al (2008) X-linked ichthyosis (steroid sulfatase deficiency) is associated with increased risk of attention deficit hyperactivity disorder, autism and social communication deficits. J Med Genet 45:519-524

14. Zaffanello M, Zamboni G, Fontana E, Zoccante L, Tato L (2003) A case of partial biotinidase deficiency associated with autism. Child Neuropsychol 9:184-188

15. Benvenuto A, Moavero R, Alessandrelli R, Manzi B, Curatolo P (2009) Syndromic autism: causes and pathogenetic pathways. World J Pediatr 5:169-176

16. Luder A, Mamet R, Farbstein I, Schoenfeld N (2009) Awareness is the name of the game: clinical and biochemical evaluation of a case diagnosed with acute intermittent porphyria associated with autism. Cell Mol Biol 55:19-22

17. Al-Owain M, Kaya N, Al-Shamrani H, Al-Bakheet A, Qari A, Al-Muaigl S, Ghaziuddin M (2013) Autism spectrum disorder in a child with propionic academia. JIMD rep. 7:63-66

18. Zafeiriou D, Ververi A, Salomons G, Vargiami E, Haas D, Papadopoulou $\mathrm{V}$ et al (2008) L-2-Hydroxyglutaric aciduria presenting with severe autistic features. Brain Dev 30:305-307

19. Kaluzna-Czaplinska J, Zurawicz E, Michalska M, Rynkowski $\mathrm{J}$ (2013) A focus on homocysteine in autism. Acta Biochim Pol 60:137-142

20. Weissman J, Kelley R, Bauman M, Cohen B, Murray K, Mitchell R et al (2008) Mitochondrial disease in autism spectrum disorder patients: a cohort analysis. PLoS One 3:e3815

21. Oliveira G, Diogo L, Grazina M, Garcia P, Ataide A, Marques $\mathrm{C}$ et al (2005) Mitochondrial dysfunction in autism spectrum disorders: a population-based study. Dev Med Child Neurol 47:185-189

22. Poling J, Frye R, Shoffner J, Zimmerman A (2006) Developmental regression and mitochondrial dysfunction in a child with autism. J Child Neurol 21:170-172

23. Spilioti M, Evangeliou A, Tramma D, Theodoridou Z, Metaxas S, Michailidi E et al (2013) Evidence for treatable inborn errors of metabolism in a cohort of 187 Greek patients with autism spectrum disorder (ASD). Front Hum Neurosc 7:858

24. Antshel K (2010) ADHD, learning, and academic performance in phenylketonuria. Mol Gen Met 99:S52-S58 
25. Antshel K, Waisbren S (2003) Developmental timing of exposure to elevated levels of phenylalanine is associated with ADHD symptom expression. J Abnorm Child Psychol 31:565-574

26. Arnold G, Vladutiu C, Orlowski C, Blakely E, Deluca J (2004) Prevalence of stimulant use for attentional dysfunction in children with phenylketonuria. J Inherit Metab Dis 27:137-143

27. Darin N, Andersen O, Wiklund L, Holmgren D, Holme E (2007) 3-methylcrotonyl-CoA carboxylase deficiency and severe multiple sclerosis. Pediatr Neurol 36:132-134

28. Nagamani S, Erez A, Lee B (2011) Argininosuccinate lyase deficiency. In: Pagon R, Adam M, Bird T, Dolan C, Fong C, Smith R, Stephens K (eds) GeneReviews. Seattle (WA), University of Washington, Seattle, 1993-2013

29. Berry G, Fukao T, Mitchell G, Mazur A, Ciafre M, Gibson J et al (2001) Neonatal hypoglycaemia in severe succinyl-CoA: 3-oxoacid CoA-transferase deficiency. J Inherit Metabol Dis 2001(24):587-595

30. Wijburg F, Wegrzyn G, Burton B, Tylki-Szymanska A (2013) Mucopolysaccharidosis type III (Sanfilippo syndrome) and misdiagnosis of idiopathic developmental delay, attention deficit/ hyperactivity disorder or autism spectrum disorder. Acta Pediatrica 102:462-470

31. Bakos J, Goen P, Ogden A, Brown F (1995) Karaviti. Adrenoleukodystrophy: a link between adrenal insufficiency and school performance. J Clin Endocrinol Metab 80:2869-2872

32. Kotagal S, Geller T, Wall D, Lastra C (1999) A child with reading impairment and a family history of adrenoleukodystrophy. Semin Pediatr Neurol 6:233-236 (discussion 236-7)

33. Weber Byars A, Mcellop J, Gyato K, Sullivan T, Franz D (2001) Metachromatic leukodystrophy and nonverbal learning disability: neuropsychological and neuroradiological findings in heterozygous carriers. Child Neuropsychol 7:54-58

34. Gordon N, Newton R (2000) Glucose transporter type1 (GLUT1) deficiency. Brain Dev 25:477-480

35. Anderson P, Wood S, Francis D, Coleman J, Anderson V, Boneh A (2007) Are neuropsychological impairments in children with early-treated phenylketonuria (PKU) related to white matter abnormalities or elevated phenylalanine levels? Dev Neuropsychol 32:645-668

36. Janzen D, Nguyen M (2010) Beyond executive function: nonexecutive cognitive abilities in individuals with PKU. Mol Gen Met 99:S47-S51

37. Tuchman M, Lee B, Lichter-Konecki U, Summar M, Yudkoff M, Cederbaum $S$ et al (2008) Cross-sectional multicenter study of patients with urea cycle disorders in the United States. Mol Gen Met Mol Gen Met 94:397-402

38. Lichter-Konecki U, Caldovic L, Morizono H, Simpson K (2013). In: Pagon R, Adam M, Dolan C, Fong C, Stephens K (eds.) GeneReviews. Seattle(WA), University of Washington, Seattle, 1993-2013

39. Potter N, Lazarus J, Johnson J, Steiner R, Shriberg L (2008) Correlates of language impairment in children with galactosaemia. $\mathrm{J}$ Inherit Metab Dis 31:524-532

40. Bahi-Buisson N, Roze E, Dionisi C, Escande F, Valayannopoulos V, Feillet F et al (2008) Neurological aspects of hyperinsulinism-hyperammonaemia syndrome. Dev Med Child Neurol 50:945-949

41. Patil N, Shinde S, Karande S, Kulkarni M (2004) Glutaric aciduria type I associated with learning disability. Indian J Pediatr 71:948

42. Walter J, Roberts R, Besley G, Wraith J, Cleary M, Holton J et al (1999) Generalised urindine diphosphate galactose-4-epimerase deficiency. Arch Dis Child 4:374-376

43. Sévin M, Lesca G, Baumann N, Millat G, Lyon-Caen O, Vanier M, Sedel F (2007) The adult form of Niemann-Pick disease type C. Brain 130:120-133
44. Pérez-Poyato M, Milà Recansens M, Ferrer Abizanda I, Montero Sanchez R, Rodriguez-Revenga L, Cusi Sanchez V (2012) Juvenile neuronal ceroid lipofuscinosis: clinical course and genetic studies in Spanish patients. J Inherit Metab Dis 34:1083-1093

45. Brady J, trehan A, Landis D, Toro C (2013) Mucopolysaccharidosis type IIIB (MPS IIIB) masquerading as a behavioural disorder. BMJ Case Rep 8:2013

46. Gutschalk A, Harting I, Cantz M, Springer C, Rohrschneider K, Meinck H (2004) Adult alpha-mannosidosis: clinical progression in the absence of demyelination. Neurology 63:1744-1746

47. Malm D, Nilssen O (2008) Alpha-mannosidosis. Orphanet J Rare Dis 3:21

48. Shapiro B, Logigian E, Kolodny E, Pastores G (2008) Late-onset Tay-Sachs disease: the spectrum of peripheral neuropathy in 30 affected patients. Muscle Nerve 38:1012-1015

49. Staretz-Chacham O, Choi J, Wakabayashi K, Lopez G, Sidransky E (2010) Psychiatric and behavioral manifestations of lysosomal storage disorders. Am J Med Genet B Neuropsychiatr Genet 5:1253-1265

50. Gairing S, Wiest R, Metzler S, Theodoridou A, Hoff P (2011) Fabry's disease and psychosis: causality or coincidence? Psychopathology 44:201-204

51. Finsterer $\mathbf{J}$ (2008) Cognitive decline as a manifestation of mitochondrial disorders (mitochondrial dementia). J Neurol Sci 272:20-33

52. Maurer I, Zierz S, Moller H (2001) Evidence for a mitochondria oxidative phosphorylation defect in brains from patients with schizophrenia. Schizophr Res 48:125-136

53. Jukic I, Titlic M, Tonkic A, Dodig G, Rogosic V (2006) Psychosis and Wilson's disease: a case report. Psychiatr Danub 18:105-107

54. Kumawat B, Sharma C, Tripathi G, Ralot T, Dixit S (2007) Wilson's disease presenting as isolated obsessive-compulsive disorder. Indian J Med Sci 61:607-610

55. Srinivas K, Sinha S, Taly A, Prashanth L, Arunodaya G, Janardhana $\mathrm{R}$ et al (2008) Dominant psychiatric manifestations in Wilson's disease: a diagnostic and therapeutic challenge! J Neurol Sci 266:104-108

56. Colsch B, Afonso C, Turpin J, Portoukalian J, Tabet J, Baumann $\mathrm{N}$ (2008) Sulfogalactosylceramides in motor and psycho-cognitive adult metachromatic leukodystrophy: relations between clinical, biochemical analysis and molecular aspects. Biochim Biophys Acta 1780:434-440

57. Altintoprak A, Ersel M, Bayrakci A (2009) An unusual suicide attempt: a case with psychosis during an acute porphyric attack. Eur J Emerg Med 16:106-108

58. Muntjewerff J, Hoogendoorn M, Kahn R, Sinke R, Den Heijer M, Kluijtmans L et al (2005) Hyperhomocysteinemia, methylenetetrahydrofolate reductase 677TT genotype, and the risk for schizophrenia: a Dutch population based case-control study. Am J Med Genet B Neuropsychiatr Genet 5:69-72

59. Sandu S, Jackowski-Dohrmann S, Ladner A, Haberhausen M, Bachman C (2009) Niemann-Pick disease type C1 presenting with psychosis in a adolescent male. Eur Child Adolesc Psychiatry 18:583-585

60. Walterfang M, Fietz M, Fahey M, Sullivan D, Leane P, Lubman D, Velakoulis D (2006) The neuropsychiatry of Niemann-Pick type C in adulthood. J Neuropsychiatry Clin Neurosci 18:158-170

61. Touati G, Valayannopoulos V, Mention K, de Longay P, Jouvet P, Depondt E et al (2006) Methylmalonic and propionic acidurias: management without or with a few supplements of specific amino acid mixture. J Inherit Metab Dis 29:288-298

62. Deutsch S, Rosse R, Yaseen M, Schulman H, Abraham S (2007) Mitochondrial myopathy complicated by eating disorders: a case report highlighting the potential interaction of genetic, metabolic, and psychodynamic factors. CNS Spectr 12:289-292 
63. Kim A, Francis J, Manos G (2009) A case of MELAS presenting as anorexia nervosa. CNS Spectr 14:531-534

64. Feddersen B, LA DE Fontaine L, Sass J, Lutz J, Abicht A, Klopstock T et al (2009) Mitochondrial neurogastrointestinal encephalomyopathy mimicking anorexia nervosa. Am J Psychiatry 166:494-495

65. Gardeitchik T, Humphrey M, Nation J, Boneh A (2012) Early clinical manifestations and eating patterns in patients with urea cycle disorders. J Pediatr 161:328-332

66. Schiff M, Benoist JF, Aïssaoui S, Boespflug-Tanguy O, Mouren MC et al (2011) Should metabolic disease be systematically screened in nonsyndromic autism spectrum disorders? PLoS ONE 6:e21932

67. Enns G, O'Brien W, Kobayashi K, Shinzawa H, Pelligrino J (2005) Postpartum, "psychosis" in mild argininosuccinate synthetase deficiency. Obstet Gynecol 105:1244-1246
68. Peterson D (2003) Acute postpartum mental status change and coma caused by previously undiagnosed ornithine transcarbamylase deficiency. Obstet Gynecol 102:1212-1215

69. Fassier T, Guffon N, Acquaviva C, D'Amato T, Durand D, Domenech P (2011) Misdiagnosed postpartum psychosis revealing a late-onset urea cycle disorder. Am J Psychiatry 168:576-580

70. Lichtenberg P, Navon R, Wertman E, Dasberg H, Lerer B (1988) Post-partum psychosis in adult GM2 gangliosidosis. A case report. Br J Psychiatry 153:387-389

71. Michot JM, Sedel F, Giraudier S, Smiejan JM, Papo T (2008) Psychosis, paraplegia and coma revealing methylenetetrahydrofolate reductase deficiency in a 56-year-old woman. J Neurol Neurosurg Psychiatry 79:963-964 